\title{
Effect of annealing treatment on microstructures and properties of austenite-based Fe-28Mn-9Al-0.8C lightweight steel with addition of $\mathrm{Cu}$
}

\author{
Zhuo Chen, Ming-xiang Liu, Jian-kang Zhang, Lei Yang, Yun-hu Zhang, *Chang-jiang Song, Qi-jie Zhai \\ Center for Advanced Solidification Technology (CAST), School of Materials Science and Engineering, Shanghai University, \\ Shanghai 200444, China
}

\begin{abstract}
The mechanical properties of an austenite-based Fe-Mn-Al-C lightweight steel were improved by co-precipitation of nanoscale Cu-rich and k-carbide particles. The Fe-28Mn-9Al-0.8C- $(0,3) \mathrm{Cu}$ (wt. \%) strips were near-rapidly solidified and annealed in the temperature range from $500{ }^{\circ} \mathrm{C}$ to $700{ }^{\circ} \mathrm{C}$. The microstructure evolution and mechanical properties of the steel under different annealing processes were studied. Microstructural analysis reveals that nanoscale $\mathrm{K}$-carbides and Cu-rich particles precipitate in the austenite and ferrite of the steel in this annealing temperature range. Co-precipitation of nanoscale $\mathrm{Cu}$-rich particles and $\mathrm{K}$-carbides provides an obvious increment in the yield strength. At the annealing temperature of $600{ }^{\circ} \mathrm{C}$, both the yield strength and ultimate tensile strength of Fe-28Mn-9Al-0.8C-3Cu (wt.\%) steel strip are the highest. The total elongation is $25 \%$, which is obviously higher than that of Cu-free steel strips, for the addition of $\mathrm{Cu}$ reduces the large sized $\mathrm{K}$-carbides precipitated along austenite/ferrite interfaces. When the annealing temperature rises to $700{ }^{\circ} \mathrm{C}$, the strength and ductility of the two steel strips deteriorate due to the formation of massive intergranular K-carbides precipitated along austenite/ferrite interfaces. It can be concluded that a proper co-precipitation of Cu-rich particles and $\mathrm{k}$-carbides would improve the properties of austenite-based Fe-Mn-Al-C steel.
\end{abstract}

Key words: austenite-based steel; Cu-rich particle; near-rapid solidification; co-precipitation strengthening; annealing treatment

CLC numbers: TG142.25 Document code: A Article ID: 1672-6421(2021)03-207-10

\section{Introduction}

Fe-Mn-Al-C steels have a great application potential in the automotive industry due to their good ductility and formability, low density and attractive mechanical properties ${ }^{[1-7]}$. They are mainly used in the structural parts of automobile body to reduce the weight of the automobile ${ }^{[8-10]}$. Austenite-based Fe-Mn-Al-C steels have high ultimate tensile strength $(700-1,100 \mathrm{MPa})$, which is superior to ferrite-based Fe-Mn-Al-C steels $(<900 \mathrm{MPa})$, and total elongation can reach $60 \%$. The density can also be reduced to $6.7-7.0 \mathrm{~g} \cdot \mathrm{cm}^{-3}$. However, the yield strength of austenite-based Fe-MnAl-C steels is low $(360-540 \mathrm{MPa})^{[11-16]}$, which restricts

\section{*Chang-jiang Song}

Ph.D., Professor. His research interests mainly focus on metal theory and microstructure control, and super performance metastable engineering materials through solidification process control. He has supervised over 20 projects and published more than 100 papers in international journals.

E-mail: riversong@shu.edu.cn; riversxiao@163.com

Received: 2021-02-05; Accepted: 2021-04-15 the application of austenite-based Fe-Mn-Al-C steels. Therefore, the yield strength of austenite-based Fe-MnAl-C steels needs to be further improved. Precipitation of $\kappa$-carbide particles in these steels can effectively improve the yield strength, but the strengthening effect of $\kappa$-carbides is not enough in many cases due to its low hardening ability, especially for austenitic Fe-Mn-Al-C lightweight steel with high $\mathrm{Mn}^{[17-20]}$.

$\mathrm{Cu}$ is often used to enhance the strength of steels through the formation of nanoscale $\mathrm{Cu}$-rich particles in the matrix, and it can improve the properties of cold formability and corrosion resistance ${ }^{[21-28]}$. Compared with $\mathrm{Mo}, \mathrm{Ni}, \mathrm{V}$ and $\mathrm{Nb}$, which are usually added into Fe-Mn-Al-C steel to achieve precipitation strengthening, the cost of $\mathrm{Cu}$ is relatively lower. The precipitation strengthening of $\mathrm{Cu}$-rich particles has been widely studied ${ }^{[29-33]}$. For example, Ren et al. ${ }^{[21]}$ reported that fine dispersed $\mathrm{Cu}$-rich particles precipitated in a super $304 \mathrm{H}$ steel led to an significant increase of hardness. $\mathrm{Xi}$ et al. ${ }^{[32]}$ obtained a $316 \mathrm{~L}$ stainless steel with high strength and good ductility by the precipitation of nanoscale $\mathrm{Cu}$-rich precipitates. 
Combining the precipitation of $\mathrm{Cu}$-rich particles and another type of precipitate usually achieves a better effect in increasing strength of steel ${ }^{[34-37]}$. Jiao et al. ${ }^{[35]}$ reported an ultra-high strength steel achieved by co-precipitation of nanoscale $\mathrm{NiAl}$ and $\mathrm{Cu}$ particles, whose tensile strength reached $1.9 \mathrm{GPa}$. Li et al. ${ }^{[37]}$ obtained another ultrahigh strength steel by nanoscale $\mathrm{Cu}$ and $\mathrm{Ni}_{3} \mathrm{Al}$ particles strengthening. Therefore, in this study, a method to improve the strength of austenitic-based Fe-Mn-Al-C lightweight steels by co-precipitation of $\mathrm{Cu}$-rich particles and $\kappa$-carbides is proposed.

Previous studies ${ }^{[38-42]}$ showed that near net-shape method under near-rapid solidification conditions is a simple method to produce Fe-Mn-Al-C steel strips with high properties. So, a centrifugal casting method was used to directly produce the strips in this work. A proper annealing treatment for Fe-Mn-Al-C steels can promote the precipitation of intragranular $\kappa$-carbide in austenite and $\mathrm{B}_{2}$ or $\mathrm{DO}_{3}$ phase in ferrite, so that the alloy can achieve better mechanical properties. The conventional annealing temperature of Fe-Mn-Al-C steels is between $450{ }^{\circ} \mathrm{C}-700{ }^{\circ} \mathrm{C}^{[2,14,42]}$. The effect of annealing temperature on the microstructures and properties of the Fe-28Mn-9Al-0.8C-(0,3)Cu (wt.\%) lightweight steels was examined.

\section{Experimental procedure}

The nominal compositions of the studied steels are Fe-28Mn9Al-0.8C- $(0,3) \mathrm{Cu}$ (wt.\%), which are named as $0 \mathrm{Cu}$ and $3 \mathrm{Cu}$ steel, respectively. The strips were prepared by a centrifugal casting equipment, as shown in Fig. $1{ }^{[43]}$. Firstly, the ingots were prepared using a vacuum induction furnace in Ar atmosphere. Then the ingots were remelted by an induction coil of the centrifugal casting equipment, and the melt flowed into a copper mould which rotated at a speed of $600 \mathrm{r} \cdot \mathrm{min}^{-1}$. The size of the obtained strips is $75 \mathrm{~mm} \times 60 \mathrm{~mm} \times 2.5 \mathrm{~mm}$, and the maximum cooling rate was about $5 \times 10^{3} \mathrm{~K} \cdot \mathrm{s}^{-1}{ }^{[44]}$. Some strips were annealed at $500{ }^{\circ} \mathrm{C}, 600{ }^{\circ} \mathrm{C}, 700{ }^{\circ} \mathrm{C}$ for $3 \mathrm{~h}$ by a tubular vacuum furnace (at a vacuum of $10^{-4} \mathrm{~Pa}$ ), and then furnace cooling to room temperature. The chemical compositions of the strips were measured by using inductively coupled plasma-atomic emission spectrometry (ICP-AES), and the results are shown in Table 1.

The microstructures of the strips were examined by using a scanning electron microscope (SEM, Hitachi SU-1500, Japan) after mechanical polishing and chemical etching at $70{ }^{\circ} \mathrm{C}$ for 30 $\mathrm{s}$ in a mixed solution of supersaturated picric acid $(94 \mathrm{~mL}), 10 \%$

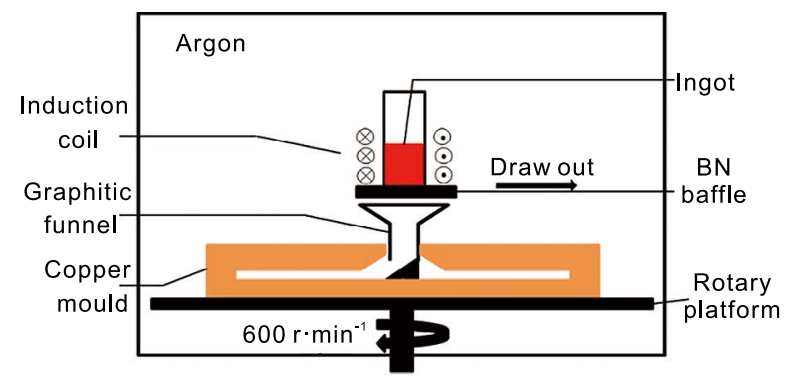

Fig. 1: Schematic illustration of centrifugal casting equipment ${ }^{[43]}$
Table 1: Measured composition of two strips (wt.\%)

\begin{tabular}{cccccc} 
Steel & $\mathrm{Mn}$ & $\mathrm{Al}$ & $\mathrm{C}$ & $\mathrm{Cu}$ & $\mathrm{Fe}$ \\
\hline $0 \mathrm{Cu}$ & 27.88 & 8.10 & 0.84 & 0 & Bal. \\
$3 \mathrm{Cu}$ & 26.67 & 8.41 & 0.81 & 2.82 & Bal.
\end{tabular}

hydrochloric acid $(3 \mathrm{~mL})$ and dodecyl benzene sulfonic acid (3 mL). X-ray diffraction (XRD, Rigaku D/max-2200×, $\mathrm{Cu} \mathrm{K \alpha}$ target operated at $40 \mathrm{kV}$ and $60 \mathrm{~mA}$ ) and transmission electron microscope (TEM, JEM-2010F operated at $200 \mathrm{kV}$, Japan) were used to identify the phases in the strips. TEM specimens were mechanically polished to a thickness of $50 \mu \mathrm{m}$, cut into a $3 \mathrm{~mm}$-diameter disc and thinned by twin-jet electropolishing in a solution of $10 \mathrm{vol} . \%$ perchloric acid $+90 \mathrm{vol} . \%$ ethyl alcohol at $-28{ }^{\circ} \mathrm{C}$ to $-32{ }^{\circ} \mathrm{C}$ with a voltage of $40 \mathrm{~V}$. Tensile tests were conducted at a strain rate of $10^{-3} \mathrm{~s}^{-1}$ at room temperature by using MTS Criterion Model 44 with $10 \mathrm{kN}$ capacity. The size of the tensile specimens is $4 \mathrm{~mm}$ in guage width and $12 \mathrm{~mm}$ in guage length, and at least three specimens were tested for each steel.

\section{Results}

\subsection{Microstructure of strips}

Figure 2 shows the phases of $0 \mathrm{Cu}$ and $3 \mathrm{Cu}$ steel strips determined by XRD. It can be seen that austenite and ferrite are the main phases in all the strips. The phase constituents of a steel strip annealed at $500{ }^{\circ} \mathrm{C}$ for $3 \mathrm{~h}$ have no obvious change compared with the as-cast strip. However, when the annealing temperature is raised, especially at $700{ }^{\circ} \mathrm{C}$, the diffraction peaks at position of $2 \theta=41.44^{\circ} / 48.24^{\circ}$ corresponding to $\kappa$-carbide are detected in both strips. This indicates that the precipitation of $\kappa$-carbide is promoted by annealing.

Figure 3 shows SEM images of $0 \mathrm{Cu}$ and $3 \mathrm{Cu}$ strips in different conditions. Similar to the as-cast strip, the ferrite in $3 \mathrm{Cu}$ strip annealed at $500{ }^{\circ} \mathrm{C}$ shows a fine banded shape [Fig. 3(f)], whereas massive irregular bulk ferrite exists in $0 \mathrm{Cu}$ strips [Fig. 3(b)]. As the annealing temperature increases to $600{ }^{\circ} \mathrm{C}$, the content of ferrite in the $0 \mathrm{Cu}$ and $3 \mathrm{Cu}$ samples is increased, but its size is slightly decreased. A black precipitated phase is observed in the ferrite near the phase boundary in the $\mathrm{Cu}-$ free strip [Fig. 3(c)], which is not observed in 3Cu strips [Fig. $3(\mathrm{~g})]$. As the annealing temperature further increases to 700 ${ }^{\circ} \mathrm{C}$, the black precipitated particles appear in the ferrite of both strips, and their size becomes greater.

SEM observation in high magnification and EDS analysis were carried out on the strips annealed at $600{ }^{\circ} \mathrm{C}$ for $3 \mathrm{~h}$. The results are shown in Fig. 4. It is found from Fig. 4(a) that a great number of black elongated or granular particles precipitate in the $0 \mathrm{Cu}$ strip, but few particles are observed in the $3 \mathrm{Cu}$ strip [Fig. 4(b)]. According to the energy spectrum analysis, the content of $\mathrm{Mn}$ and $\mathrm{C}$ in the precipitated phase is significantly high, as shown in Fig. 4(c). According to the literature ${ }^{[33]}$, when the annealing temperature exceeds $550{ }^{\circ} \mathrm{C}$, a part of austenite 

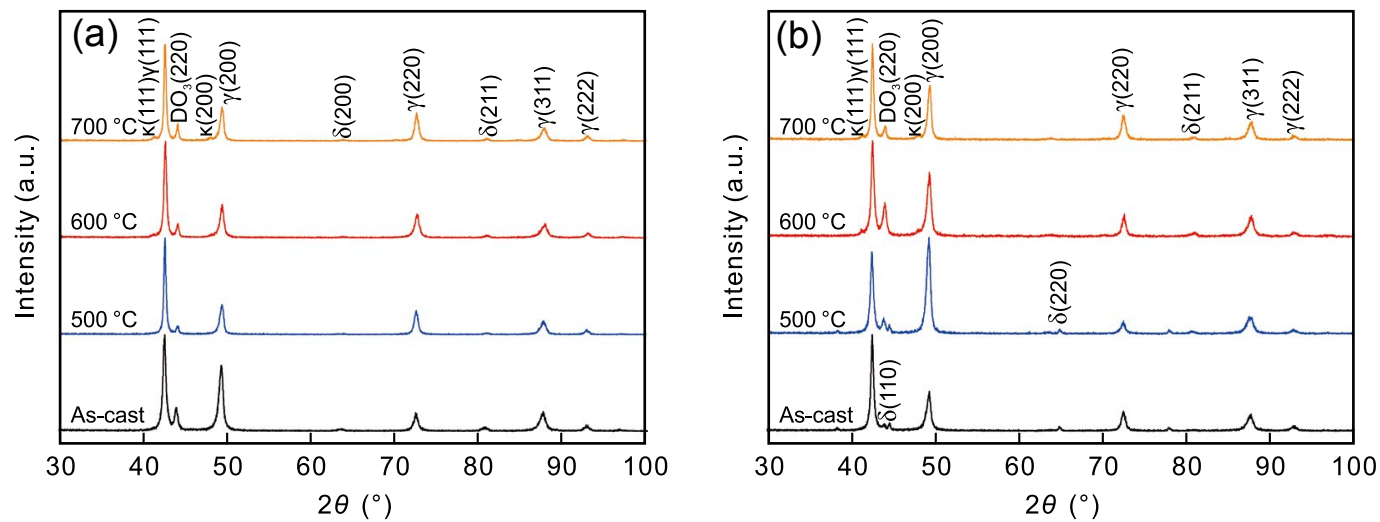

Fig. 2: X-ray diffraction patterns of steel strips: (a) $0 \mathrm{Cu}$; (b) $3 \mathrm{Cu}$
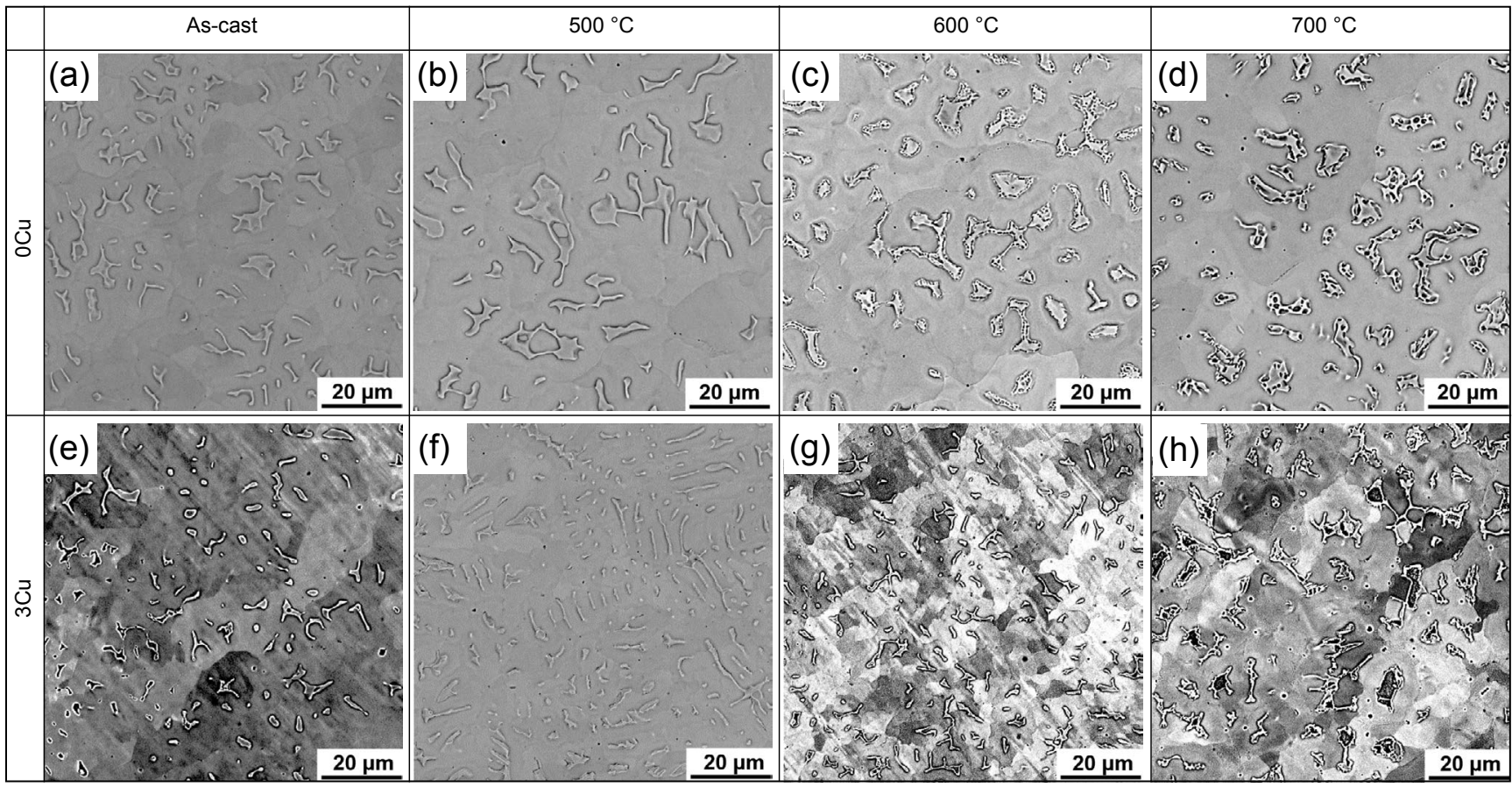

Fig. 3: Microstructures of $0 \mathrm{Cu}$ and $3 \mathrm{Cu}$ strips. $0 \mathrm{Cu}$ : (a) as-cast; (b) $500^{\circ} \mathrm{C}$; (c) $600{ }^{\circ} \mathrm{C}$; (d) $700{ }^{\circ} \mathrm{C}$; $3 \mathrm{Cu}$ : (e) as-cast; (f) $500^{\circ} \mathrm{C}$; (g) $600^{\circ} \mathrm{C}$; (h) $700^{\circ} \mathrm{C}$
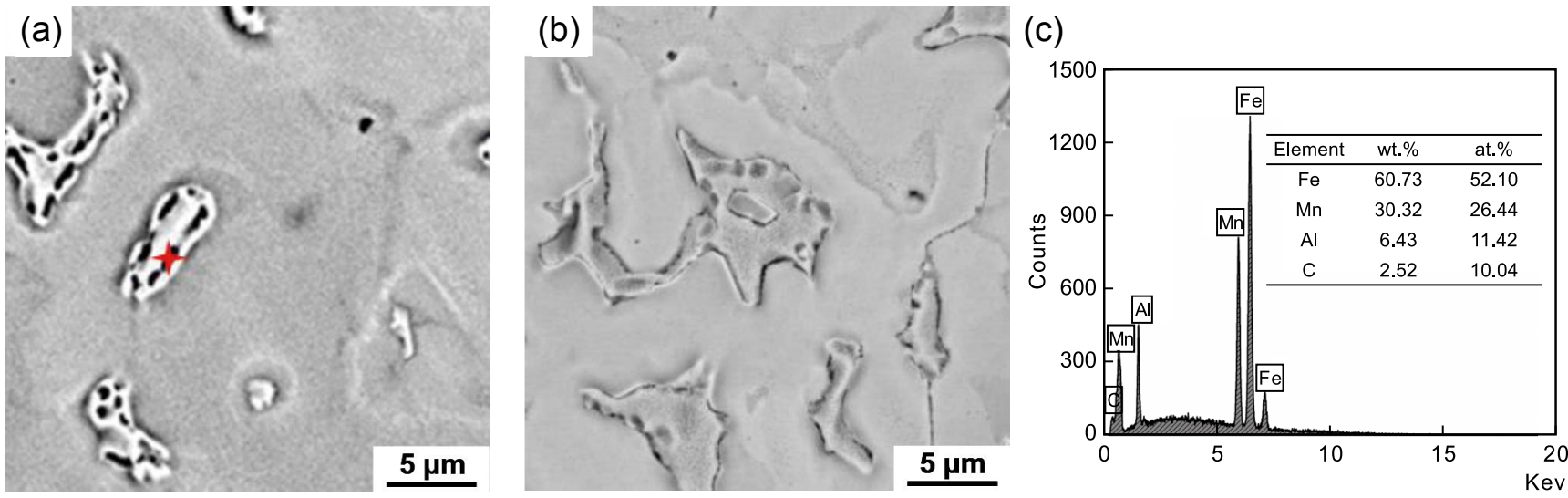

Fig. 4: High magnification SEM images of strips annealed at $600^{\circ} \mathrm{C}$ : (a) $0 \mathrm{Cu}$; (b) $3 \mathrm{Cu}$; (c) EDS analysis of precipitation in (a)

would be transformed into ferrite and intergranular $\kappa$-carbide in some austenite matrix lightweight steels, so the black precipitation is determined as $\kappa$-carbide. It can be concluded that the addition of $3 \mathrm{wt} . \% \mathrm{Cu}$ reduces the precipitation of $\kappa$-carbide along austenite/ferrite interfaces in the strip annealed at $600{ }^{\circ} \mathrm{C}$ for $3 \mathrm{~h}$. 


\subsection{Mechanical properties}

Figures 5(a) and (b) show the engineering stress-strain curves of $0 \mathrm{Cu}$ and $3 \mathrm{Cu}$ steel strips, respectively. The detailed values for the mechanical properties including yield strength (YS), ultimate tensile strength (UTS) and total elongation (TE) are listed in Table 2. Results show that when $3 \mathrm{wt} . \% \mathrm{Cu}$ is added, the YS and UTS of Fe-28Mn-9Al-0.8C as-cast strips are reduced by $30-50 \mathrm{MPa}$, but its elongation increases slightly. After annealing treatment, the strength of both $\mathrm{Cu}$-containing and $\mathrm{Cu}$-free steel strips increases significantly compared with as-cast steel strip. The increases in YS and UTS of $3 \mathrm{Cu}$ steel strip are obviously higher than those of the $\mathrm{Cu}$-free steel strip
[Figs. 5(c) and (d)], which makes YS and UTS of 3Cu strip exceed those of $\mathrm{Cu}$-free strip by $30-70 \mathrm{MPa}$ after annealing at $600{ }^{\circ} \mathrm{C}$ for $3 \mathrm{~h}$. However, when the annealing temperature increases to $600{ }^{\circ} \mathrm{C}$, the elongation of $\mathrm{Cu}$-free and $\mathrm{Cu}$ containing strips clearly decreases, which should be ascribed to the greater precipitation of $\kappa$-carbide, especially the appearance of $\kappa$-carbide at austenite/ferrite interfaces. Moreover, when the annealing temperature reaches to $700{ }^{\circ} \mathrm{C}$, the strength of the two steel strips is also clearly reduced. Generally, the elongation of $\mathrm{Cu}$-containing strips under the same condition is slightly better than that of $\mathrm{Cu}$-free strip except the strips annealed at $700{ }^{\circ} \mathrm{C}$. (a)

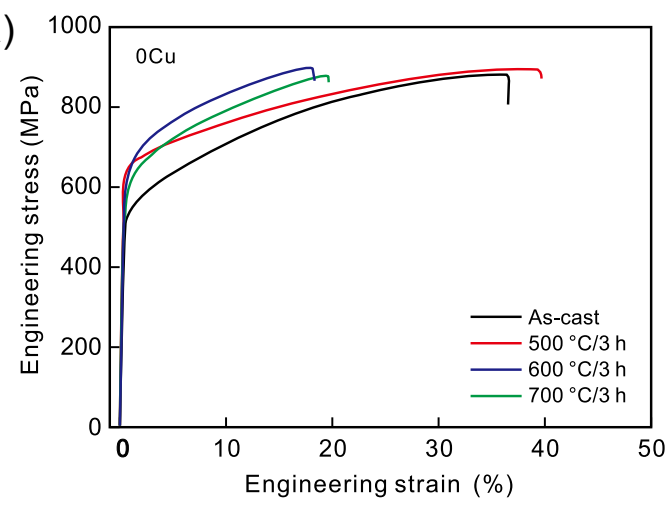

(c)

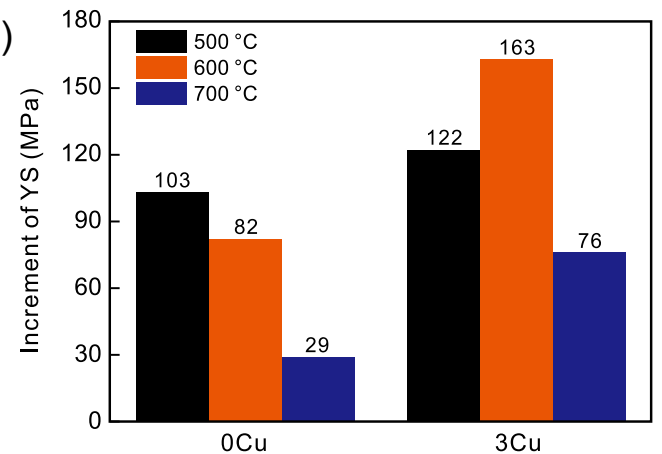

(b)

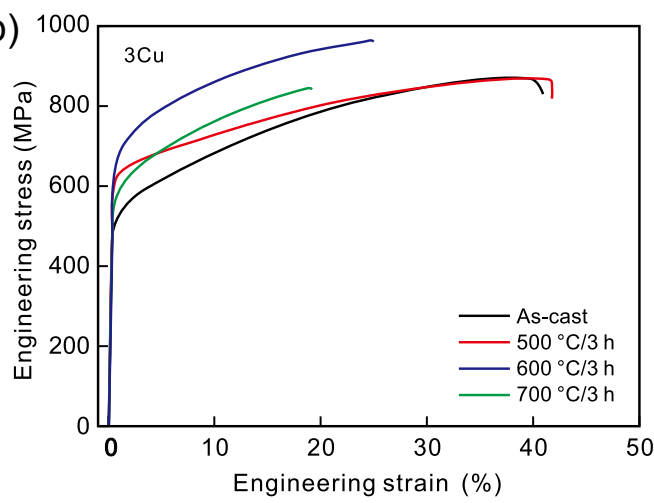

(d)

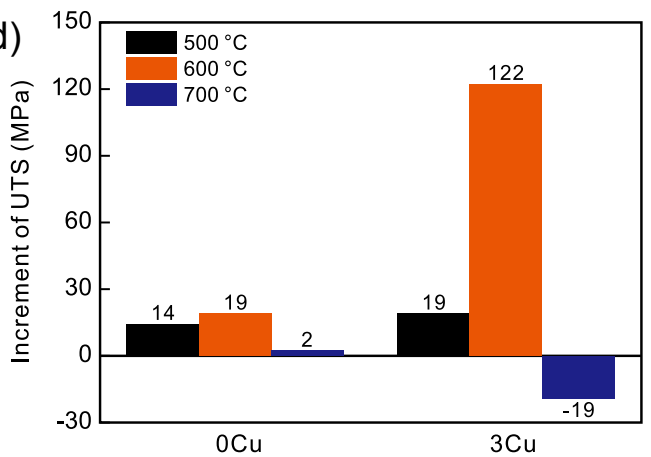

Fig. 5: Engineering stress-strain curves of strips: (a) $0 \mathrm{Cu}$; (b) $3 \mathrm{Cu}$; and increases in strength of annealed strips: (c) YS; (d) UTS

Table 2: Tensile properties of Fe-28Mn-9AI-0.8C-(0,3) Cu strips under different states

\begin{tabular}{ccccccc}
$\begin{array}{c}\text { Sample } \\
\text { state }\end{array}$ & \multicolumn{1}{c}{ OCu } & \multicolumn{3}{c}{$3 \mathrm{Cu}$} \\
As-cast & $538 \pm 19$ & $877 \pm 28$ & $35 \pm 3$ & $490 \pm 24$ & $843 \pm 30$ & $38 \pm 6$ \\
$500^{\circ} \mathrm{C} / 3 \mathrm{~h}$ & $641 \pm 5$ & $891 \pm 13$ & $39 \pm 3$ & $612 \pm 12$ & $862 \pm 15$ & $40 \pm 5$ \\
$600^{\circ} \mathrm{C} / 3 \mathrm{~h}$ & $620 \pm 11$ & $896 \pm 24$ & $17 \pm 3$ & $653 \pm 17$ & $965 \pm 23$ & $25 \pm 6$ \\
$700^{\circ} \mathrm{C} / 3 \mathrm{~h}$ & $567 \pm 4$ & $879 \pm 3$ & $20 \pm 1$ & $566 \pm 2$ & $824 \pm 20$ & $18 \pm 4$
\end{tabular}

\subsection{TEM analysis of precipitated phases}

To well understand the reason for change of the mechanical properties, TEM was performed on the $\mathrm{Cu}$-free and $\mathrm{Cu}$ containing steel strips annealed at $500{ }^{\circ} \mathrm{C}$ and $700{ }^{\circ} \mathrm{C}$, respectively.

\subsubsection{Strips annealed at $500{ }^{\circ} \mathrm{C}$}

Figure 6 shows the microstructures of $0 \mathrm{Cu}$ strip after annealing treatment at $500{ }^{\circ} \mathrm{C}$ for $3 \mathrm{~h}$. Figure 6 (a) is a bright-field (BF) image of austenite. According to a selected-area electron diffraction (SAED) pattern of austenite taken from [110] axis, 
(a)

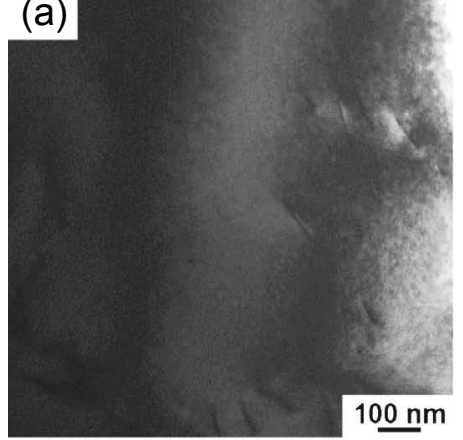

(d)

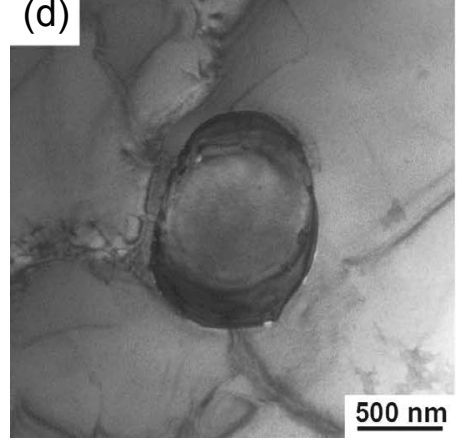

(b)

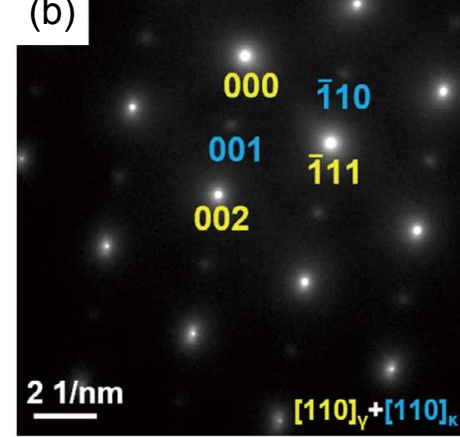

(e)

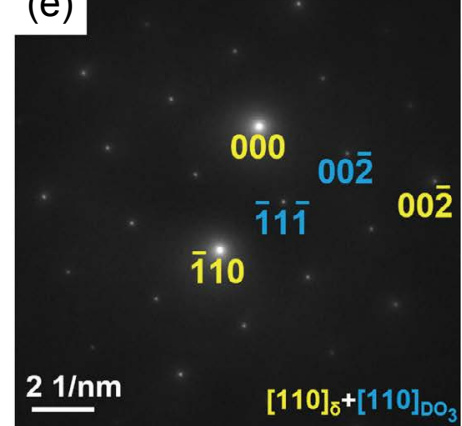

(c)

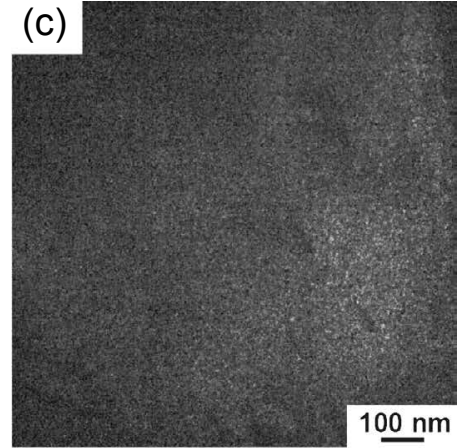

(f)

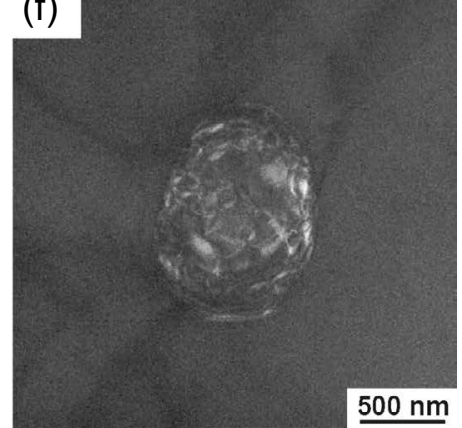

Fig. 6: TEM images of $0 \mathrm{Cu}$ steel strip after annealing at $500^{\circ} \mathrm{C}$ for $3 \mathrm{~h}$ : (a) BF image of austenite; (b) SAED pattern along [110] $]_{Y}$ zone axis from (a); (c) DF image of $K$-carbide particles; (d) BF image of ferrite; (e) SAED pattern along $[110]_{\delta}$ zone axis from (d); (f) DF image of $\mathrm{DO}_{3}$ phase

a superlattice belonging to $\kappa$-carbide is found [Fig. 6(b)]. The dark-field (DF) image [Fig. 6(c)] also indicates that there are some nanoscale $\kappa$-carbides in the austenite matrix. The SAED pattern taken from the ferrite area along $[110]_{\delta}$ axis is shown in Fig. 6(e), a diffraction spot belonging to $\mathrm{DO}_{3}$ phase can be detected. The corresponding DF image [Fig. 6(f)] illustrates that the scaly $\mathrm{DO}_{3}$ phase with a size of about $100 \mathrm{~nm}$ appears in the ferrite after annealing at $500{ }^{\circ} \mathrm{C}$ for $3 \mathrm{~h}$.

Figure 7 shows the TEM image of $3 \mathrm{Cu}$ strips annealed at $500{ }^{\circ} \mathrm{C}$ for $3 \mathrm{~h}$. A superlattice of $\kappa$-carbides also appears in the
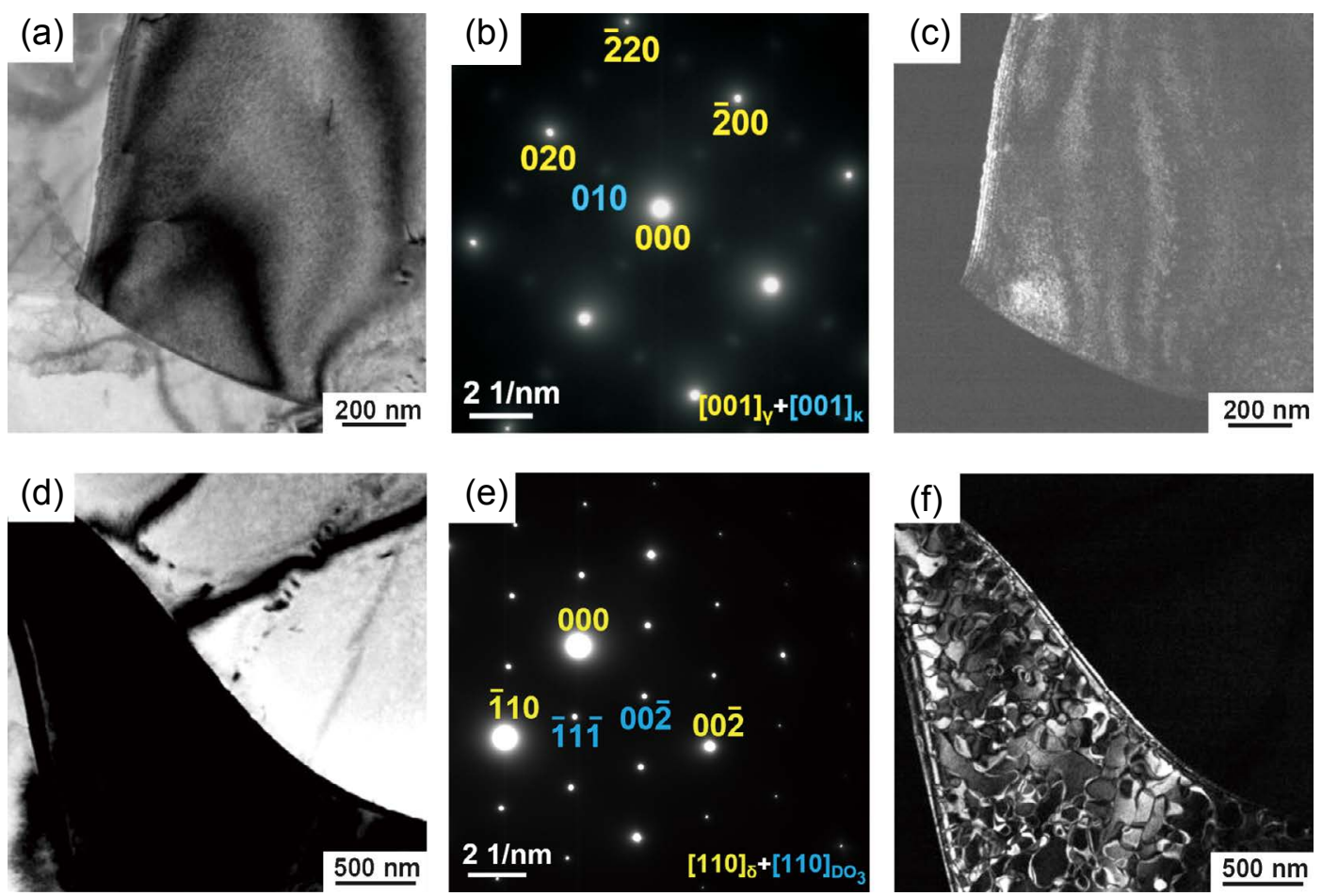

Fig. 7: TEM images of $3 \mathrm{Cu}$ steel strip after annealing at $500^{\circ} \mathrm{C}$ for $3 \mathrm{~h}$ : (a) BF image of austenite; (b) SAED pattern along [001] zone axis from (a); (c) DF image of $\mathrm{K}$-carbide particles; (d) BF image of ferrite; (e) SAED pattern along $[110]_{\delta}$ zone axis from (d); (f) $\mathrm{DF}$ image of $\mathrm{DO}_{3}$ phase 
austenitic matrix [Fig. 7(b)], and some granular $\kappa$-carbides are dispersedly precipitated in the matrix from the corresponding DF images [Fig. 7(c)]. Figure 7(e) presents SAED pattern of ferrite taken from $[110]_{\delta}$ axis, which shows there also exists a superlattice corresponding to the ordered $\mathrm{DO}_{3}$ phase in ferrite. The size and morphology of $\mathrm{DO}_{3}$ phase are similar to that of $\mathrm{Cu}$-free strips [Fig. 7(f)].

\subsubsection{Strips annealed at $700{ }^{\circ} \mathrm{C}$}

Figure 8 shows TEM images of $0 \mathrm{Cu}$ strips annealed at $700{ }^{\circ} \mathrm{C}$. According to corresponding DF images [Figs. 8(c) and (f)], there are two different morphologies of $\kappa$-carbides in austenitic matrix after annealing at $700{ }^{\circ} \mathrm{C}$. Some are granular $\kappa$-carbides with size less than $10 \mathrm{~nm}$, the others are large bulk $\kappa$-carbides. This suggests that the $\kappa$-carbides are significantly coarsening after annealing at $700{ }^{\circ} \mathrm{C}$. From the SAED pattern of ferrite taken from $[110]_{\delta}$ axis [Fig. $\left.8(\mathrm{~h})\right]$, there still exists a superlattice of $\mathrm{DO}_{3}$ ordered phase, and its dark field image is shown in Fig. 8(i).

Figure 9 presents the TEM images of $3 \mathrm{Cu}$ strips annealed at $700{ }^{\circ} \mathrm{C}$ for $3 \mathrm{~h}$. It is found that the size of $\kappa$-carbides in austenite is also greater than those of strips annealed at $500{ }^{\circ} \mathrm{C}$, but fewer large-bulk shape $\kappa$-carbides are found in $3 \mathrm{Cu}$ strips after annealing at $700{ }^{\circ} \mathrm{C}$, as shown in Figs. 9(a) and (c), indicating that the addition of $3 \mathrm{wt} . \% \mathrm{Cu}$ reduces the precipitation of coarse $\kappa$-carbides with bulk shape. Figures $9(\mathrm{~d})$ and (f) show the BF and DF images of ferrite, respectively. It can be seen that the $\mathrm{DO}_{3}$ phase in ferrite presents a water ripple shape and becomes larger compared to that of $3 \mathrm{Cu}$ strips annealed at $500{ }^{\circ} \mathrm{C}$.

\subsection{EPMA analysis of Cu precipitates}

The diffraction belonging to $\mathrm{Cu}$ precipitates is not found in the SAED pattern of austenite. Therefore, EPMA was used to analyze the distribution of $\mathrm{Cu}$ element in the $3 \mathrm{Cu}$ steel strip and the results are shown in Fig. 10.
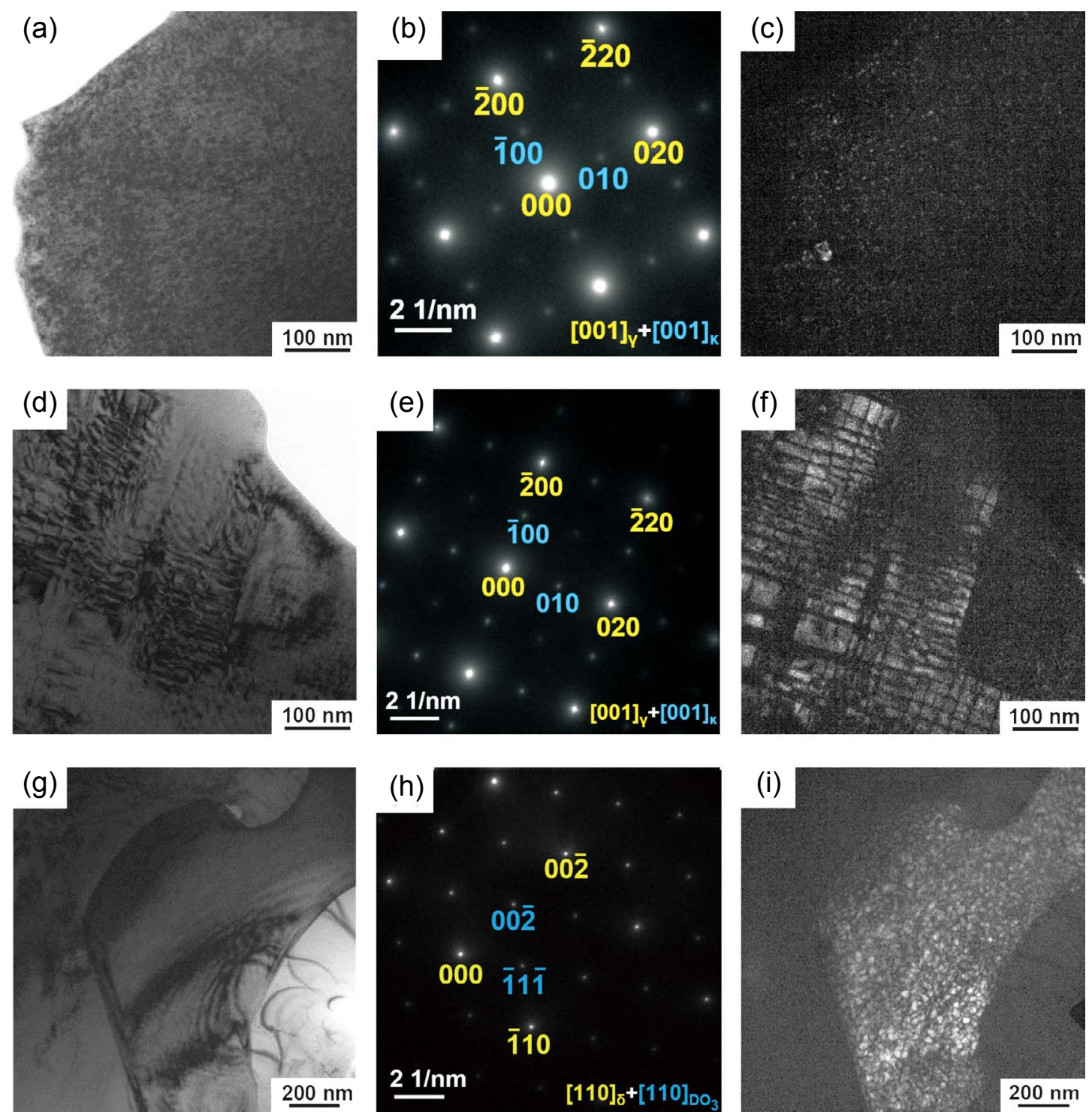

Fig. 8: TEM images of $0 \mathrm{Cu}$ steel strip after annealing at $700^{\circ} \mathrm{C}$ for $3 \mathrm{~h}$ : (a) BF image of austenite; (b) SAED pattern along [001] $]_{Y}$ zone axis from (a); (c) DF image of $K$-carbide particles; (d) BF image of austenite; (e) SAED pattern along [001] $]_{\mathrm{Y}}$ zone axis from (d); (f) DF image of k-carbide particles; (g) BF image of ferrite; (h) SAED pattern along $[110]_{\delta}$ zone axis from (g); (i) DF image of $\mathrm{DO}_{3}$ phase 
(a)
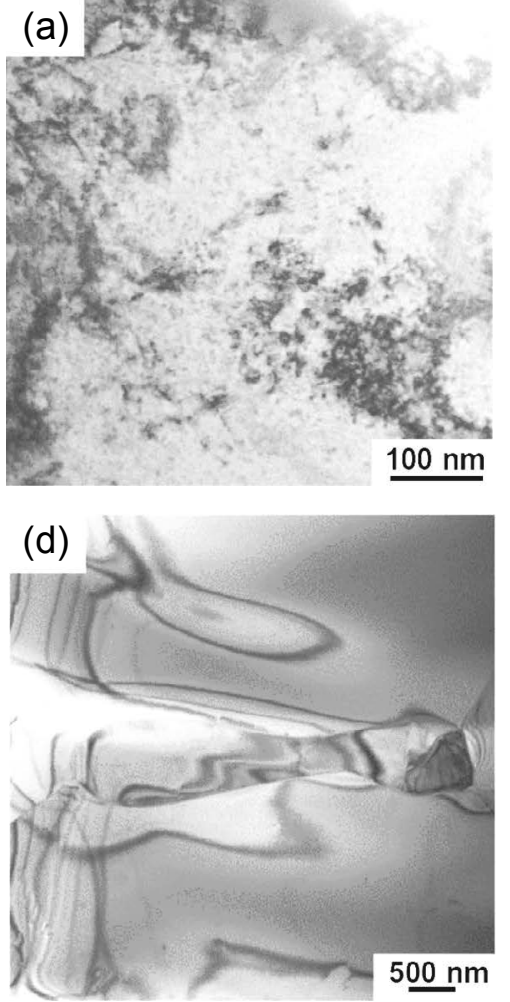

(b)

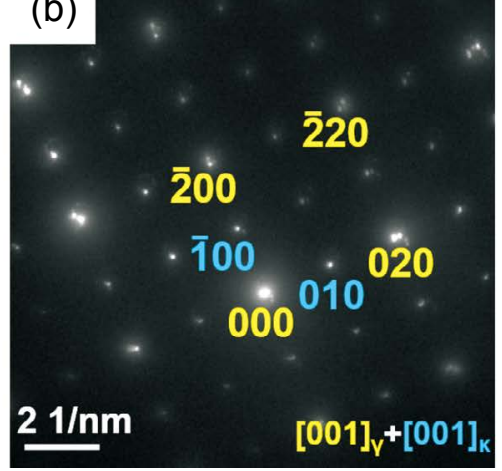

(e)

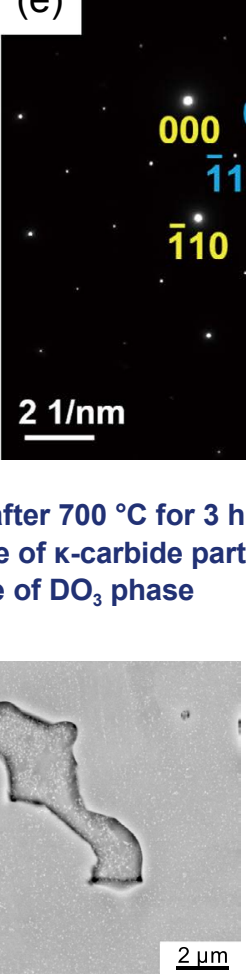

$[110]_{6}+[110]_{\mathrm{DO}_{3}}$ (c)
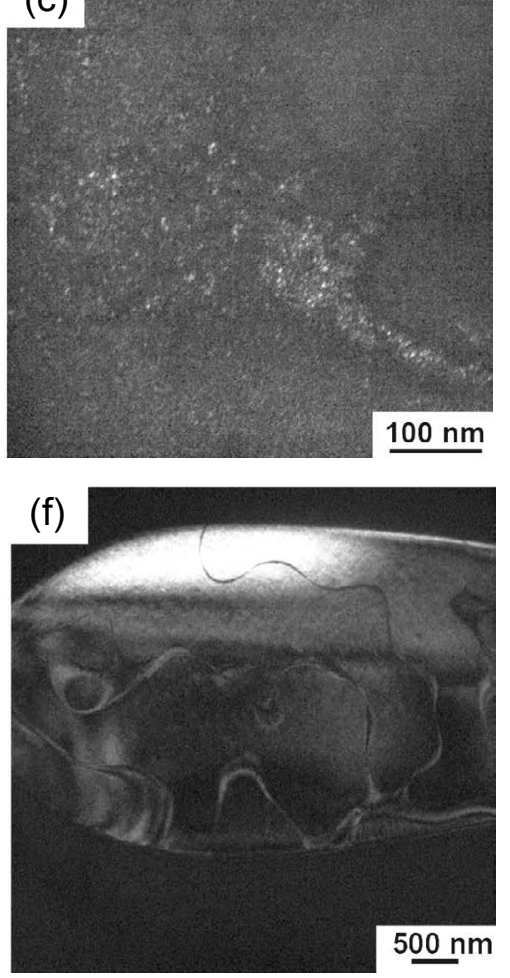

Fig. 9: TEM images of $3 \mathrm{Cu}$ steel strip after $700{ }^{\circ} \mathrm{C}$ for $3 \mathrm{~h}$ : (a) BF image of austenite; (b) SAED pattern along [001] $]_{\mathrm{Y}}$ zone axis from (a); (c) DF image of K-carbide particles; (d) BF image of ferrite; (e) SAED pattern along [110] zone axis from (d); (f) DF image of $\mathrm{DO}_{3}$ phase
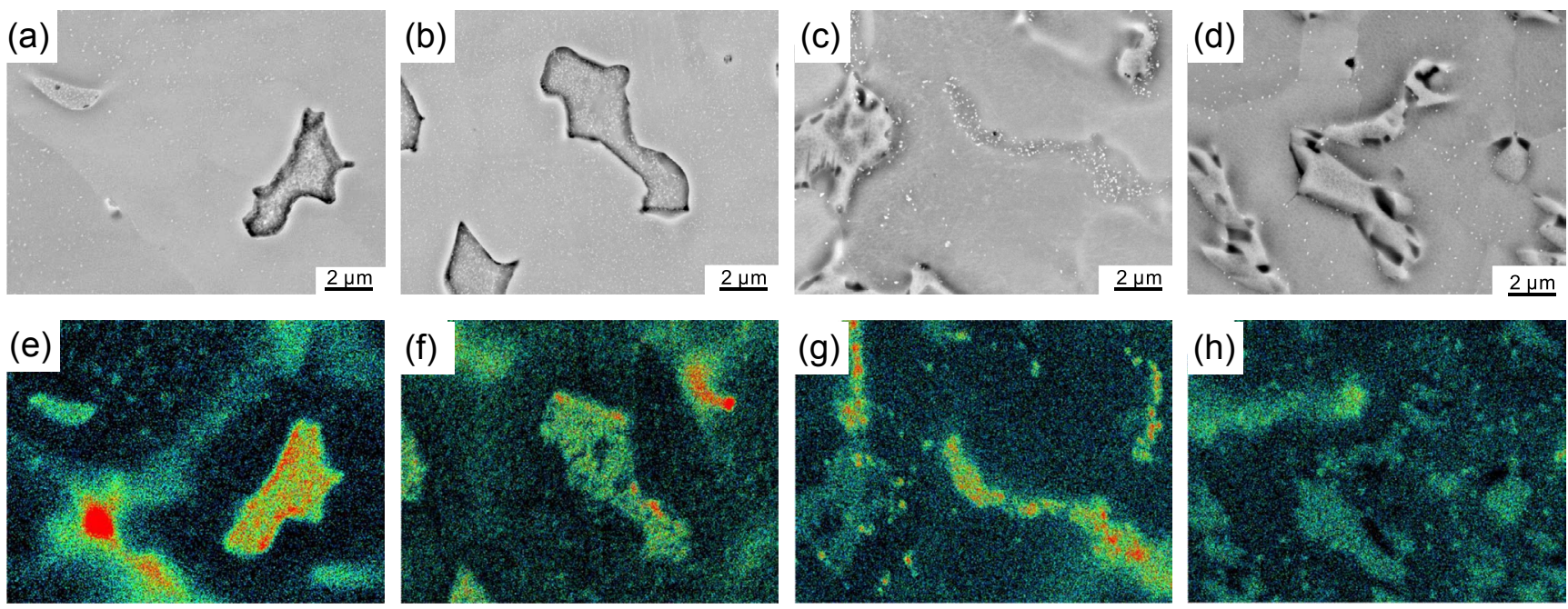

$(\operatorname{mass} \% \mathrm{Cu})$

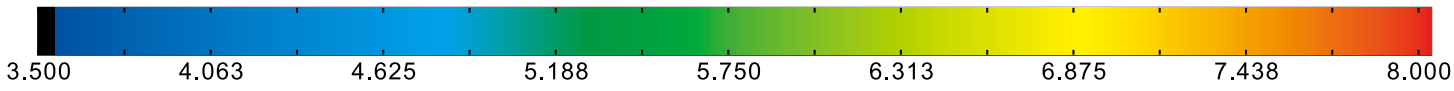

Fig. 10: EPMA images of $3 \mathrm{Cu}$ strips: (a) and (e) as-cast; (b) and (f) annealed at $500^{\circ} \mathrm{C}$; (c) and (g) annealed at $600^{\circ} \mathrm{C}$; (d) and (h) annealed at $700^{\circ} \mathrm{C}$

The results of EPMA mapping show that there are some large Cr-rich regions with high $\mathrm{Cu}$ content at the grain/phase boundary and inside the ferrite, and some small $\mathrm{Cu}$-rich regions with slightly high $\mathrm{Cu}$ content in the austenite matrix. As the annealing temperature increases, the size and number of large $\mathrm{Cu}$-rich regions gradually decrease, while the number of small $\mathrm{Cu}$-rich regions in austenite increases.

To further examine these small Cu-rich regions, a TEM equipped with energy dispersive spectrometer (TEM-EDS) was used to detect these regions in a $3 \mathrm{Cu}$ steel strip annealed at $500{ }^{\circ} \mathrm{C}$ for $6 \mathrm{~h}$ (a longer annealing time to obtain more $\mathrm{Cu}$-rich precipitates). It can be found there are a lot of $\mathrm{Cu}$-rich particles [black regions in Fig. 11(a)] in the austenite matrix, and the average size of these particles is about $45 \mathrm{~nm}$. Thus it is determined that coprecipitation of nano-scale $\mathrm{Cu}$-rich and $\kappa$-carbide particles is achieved in the $3 \mathrm{Cu}$ strips annealed at $500{ }^{\circ} \mathrm{C}$. 


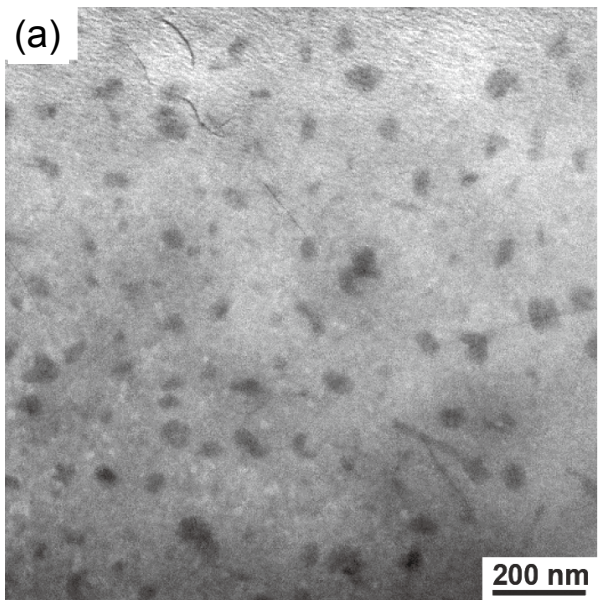

(b)
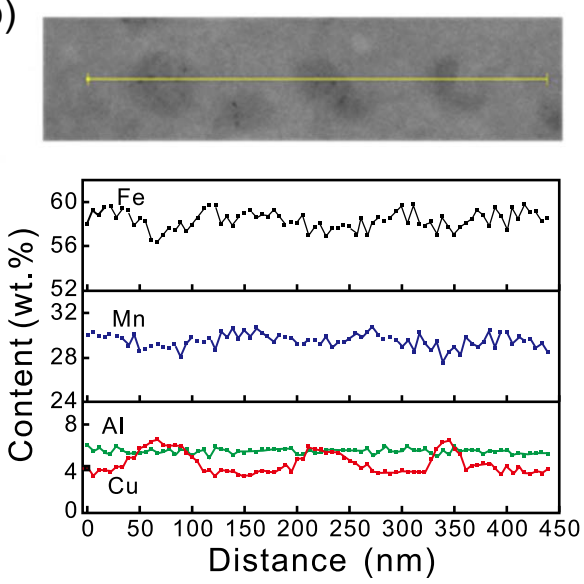

Fig. 11: TEM-EDS of $3 \mathrm{Cu}$ steel strip annealed at $500^{\circ} \mathrm{C}$ for $6 \mathrm{~h}$ : (a) mapping; (b) line scanning

\section{Discussion}

An addition of $3 \mathrm{wt} . \% \mathrm{Cu}$ decreases the yield strength of the strip in the as-cast condition due to an increase of austenite volume fraction. Austenite as a soft phase leads to the decrease in strength ${ }^{[45]}$. Moreover, $\mathrm{Cu}$ addition also causes the increase of stacking fault energy for austenitebased lightweight steels ${ }^{[46,47]}$. The increase in stacking fault energy would reduce the width of extended dislocations which is in favor of the climbing, cross-slip and mutual cutting of dislocations ${ }^{[46]}$. Therefore, the increase of austenite content and stacking fault energy of austenite matrix reduces the yield strength of $3 \mathrm{Cu}$ steel strip. After annealing, the increase in the strength of $3 \mathrm{Cu}$ steel strip is obvious. Under nearrapid solidification condition, interstitial carbon atom and substitutional $\mathrm{Cu}$ atom can be supersaturated in austenite and ferrite ${ }^{[42]}$, which means that $\delta$ ferrite and $\gamma$ austenite are metastable. Thus, the formation of nanoscale $\kappa$-carbides and $\mathrm{Cu}$-rich particles can be promoted during annealing treatment. Meanwhile, the increasing temperature can provide more thermodynamic driving force for precipitation of $\mathrm{Cu}$-rich particles and accelerate the formation of these particles ${ }^{[32]}$, and at the same time, other atoms are rejected from $\mathrm{Cu}$-rich particles resulting in an enrichment of these elements ${ }^{[48,49]}$. Thus, the formation of $\mathrm{Cu}$-rich particles could promote the precipitation of $\kappa$-carbides, and the co-precipitation of $\kappa$-carbides and $\mathrm{Cu}$-rich particles provides higher strengthening effect on the strength of $3 \mathrm{Cu}$ steel strip. When the annealing temperature reaches $700{ }^{\circ} \mathrm{C}$, the strength and total elongation of the two steel strips are decreased, which resulted by the formation of a large number of coarse $\kappa$-carbides and intergranular $\kappa$-carbides around phase boundaries. In addition, the solubility of $\mathrm{Cu}$ increases when the temperature rises ${ }^{[50]}$, which can reduce the number of $\mathrm{Cu}$-rich precipitates. The strengthening effect is weakened, leading to a decline in the strength of the steel.

The total elongation of two steel strips annealed at $500{ }^{\circ} \mathrm{C}$ increases compared with the as-cast steel strip. The reason should be a release of thermal stress after annealing treatment ${ }^{[51]}$. When annealing temperature increases, the precipitation of intergranular $\kappa$-carbides around phase boundary can result in crack initiation and propagation, which makes total elongation of the strips decrease significantly ${ }^{[52,53]}$. Compared with the $\mathrm{Cu}$ free steel strip, the total elongation of the $\mathrm{Cu}$-containing steel strip annealed at $600{ }^{\circ} \mathrm{C}$ is much higher. This is because the addition of $3 \mathrm{wt} . \% \mathrm{Cu}$ reduces the precipitation of intergranular $\kappa$-carbides in the steel strips annealed at $600{ }^{\circ} \mathrm{C}$.

\section{Conclusions}

This work mainly studied the effect of annealing temperature on the microstructures and mechanical properties of Fe-28Mn9Al-0.8C-(0,3) Cu (wt.\%) steel, an austenite-based lightweight steel strengthened by co-precipitation of $\kappa$-carbides and $\mathrm{Cu}-$ rich particles, prepared under near rapid solidification. The conclusions are obtained as follows:

(1) The near-rapidly solidified Fe-28Mn-9Al-0.8C- $(0,3) \mathrm{Cu}$ lightweight steel strips mainly contain $(\gamma+\delta)$ duplex phases. Annealing at $500{ }^{\circ} \mathrm{C}-700{ }^{\circ} \mathrm{C}$ for $3 \mathrm{~h}$ can promote the precipitation of $\kappa$-carbides in the $\gamma$ matrix of $\mathrm{Cu}$-free steel strip and achieve co-precipitation of nanoscale $\mathrm{Cu}$-rich particles and $\kappa$-carbides in the $\mathrm{Cu}$-containing steel strip. Co-precipitation of $\mathrm{Cu}$-rich particles and $\kappa$-carbides provides a high increment in yield strength.

(2) Annealing at $500{ }^{\circ} \mathrm{C}$ makes yield strength of $\mathrm{Cu}$ free and $\mathrm{Cu}$-containing steels significantly increase, and simultaneously slightly improves their ductility. A large number of intergranular $\kappa$-carbides along austenite/ferrite interfaces are formed in $\mathrm{Cu}$-free steel strips annealed at $600{ }^{\circ} \mathrm{C}$, which make its total elongation obviously decrease. An addition of $3 \mathrm{wt} . \%$ $\mathrm{Cu}$ inhibits the formation of the intergranular $\kappa$-carbides in $\mathrm{Cu}$-containing steel strip annealed at $600{ }^{\circ} \mathrm{C}$, causing a further increase in strength and small decrease in total elongation. The yield strength, ultimate tensile strength and total elongation of the $\mathrm{Cu}$-containing steel strip annealed at $600{ }^{\circ} \mathrm{C}$ are $653 \mathrm{MPa}$, $965 \mathrm{MPa}$ and $25 \%$, respectively, which are higher than those of $\mathrm{Cu}$-free steel strip. Both strength and ductility of the two steel strips annealed at $700{ }^{\circ} \mathrm{C}$ obviously decrease due to the formation of more intergranular $\kappa$-carbides. 


\section{Acknowledgements}

This work was financially supported by the National Natural Science Foundation of China (No. 51974184) and the National MCF Energy R\&D Program of China (No. 2018YFE0306102). XRD and TEM tests were conducted in the Instrumental Analysis and Research Center at Shanghai University. The authors would like to express sincere thanks for their support.

\section{References}

[1] Kim S H, Kim H, Kim N J. Brittle intermetallic compound makes ultrastrong low-density steel with large ductility. Nature, 2015, 518(7537): 77-85.

[2] Choi K, Seo $\mathrm{C} \mathrm{H}$, Lee $\mathrm{H}$, et al. Effect of aging on the microstructure and deformation behavior of austenite base lightweight Fe-28Mn-9Al-0.8C steel. Scripta Mater., 2010, 63(10): 1028-1031.

[3] Zhang L F, Song R B, Zhao C, et al. Evolution of the microstructure and mechanical properties of an austeniteferrite Fe-Mn-Al-C steel. Mater. Sci. Eng. A, 2015, 643: 183193.

[4] Yoo J D, Hwang S W, Park K T. Factors influencing the tensile behavior of a Fe-28Mn-9AI-0.8C steel. Mater. Sci. Eng. A, 2009, 508(1-2): 234-240.

[5] Sutou Y, Kamiya N, Umino R, et al. High-strength Fe-20MnAl-C-based alloys with low density. ISIJ Int., 2010, 50(6): 893899.

[6] Hwang S W, Ji J H, Lee E G, et al. Tensile deformation of a duplex Fe-20Mn-9Al-0.6C steel having the reduced specific weight. Mater. Sci. Eng. A, 2011, 528(15): 5196-5203.

[7] Ha M C, Koo J M, Lee J K, et al. Tensile deformation of a low density Fe-27Mn-12Al-0.8C duplex steel in association with ordered phases at ambient temperature. Mater. Sci. Eng. A, 2013, 586: 276-283.

[8] Frommeyer G, Brux U. Microstructures and mechanical properties of high-strength Fe-Mn-Al-C light-weight TRIPLEX steels. Steel Res. Int., 2006, 77(9-10): 627-633.

[9] Schulte A. Quality improvements of cast lightweight steel P900 armor. Int. J. Met., 2010, 4(1): 59-63.

[10] Zambrano O A. A general perspective of Fe-Mn-Al-C steels. J. Mater. Sci., 2018, 53(20): 14003-14062.

[11] Yoo J D, Hwang S W, Park K T. Origin of extended tensile ductility of a Fe-28Mn-10Al-1C steel. Metall. Mater. Trans. A, 2009, 40(7): 1520-1523.

[12] Lee K, Park S J, Moon J, et al. $\beta$-Mn formation and aging effect on the fracture behavior of high-Mn low-density steels. Scripta Mater., 2016, 124: 193-197.

[13] Xing J, Hou L F, Du H Y, et al. Effects of pre-deformation on the kinetics of $\beta-M n$ phase precipitation and mechanical properties in Fe-30Mn-9Al-1C lightweight steel. Metal Mater. Trans. A, 2019, 50(6): 2629-2639.

[14] Feng Y F, Song R B, Pei Z Z, et al. Effect of aging isothermal time on the microstructure and room-temperature impact toughness of Fe-24.8Mn-7.3Al-1.2C austenitic steel with $\mathrm{k}$-carbides precipitation. Met. Mater. Int., 2018, 24(5): 1012-1023.

[15] Yoo J D, Park K T. Microband-induced plasticity in a high MnAl-C light steel. Mater. Sci. Eng. A, 2008, 496(1-2): 417-424.

[16] Yoo J, Kim B, Park Y, et al. Microstructural evolution and solidification cracking susceptibility of Fe-18Mn-0.6C-xAl steel welds. J. Mater. Sci., 2015, 50(1): 279-286.

[17] Song W, Zhang W, Appen J V, et al. K-phase formation in FeMn-Al-C austenitic steels. Steel Res. Int., 2015, 86(10): 11611169.
[18] Park K T, Hwang S W, Son C Y, et al. Effects of heat treatment on microstructure and tensile properties of a Fe-27Mn-12Al0.8C low-density steel. JOM, 2014, 66(9): 1828-1836.

[19] Chang K M, Chao C G, Liu T F. Excellent combination of strength and ductility in an Fe-9Al-28Mn-1.8C alloy. Scr. Mater., 2010, 63(2): 162-165.

[20] He W, Wang B L, Yang Y, et al. Microstructure and mechanical behavior of a low-density Fe-12Mn-9AI-1.2C steel prepared using centrifugal casting under near-rapid solidification. J. Iron Steel Res. Int., 2018, 25(8): 830-838.

[21] Ren L, Nan L, Yang K. Study of copper precipitation behavior in a Cu-bearing austenitic antibacterial stainless steel. Mater. Des., 2011, 32(4): 2374-2379.

[22] Ren L, Zhu J M, Nan L, et al. Differential scanning calorimetry analysis on $\mathrm{Cu}$ precipitation in a high $\mathrm{Cu}$ austenitic stainless steel. Mater. Des., 2011, 32(7): 3980-3985.

[23] Tan S P, Wang Z H, Cheng S C, et al. Effect of $\mathrm{Cu}$ content on aging precipitation behaviors of $\mathrm{Cu}$-rich phase in $\mathrm{Fe}-\mathrm{Cr}-\mathrm{Ni}$ alloy. J. Iron Steel Res. Int., 2010, 17(5): 63-68.

[24] Sen I, Amankwah E, Kumar N S, et al. Microstructure and mechanical properties of annealed SUS $304 \mathrm{H}$ austenitic stainless steel with copper. Mater. Sci. Eng. A, 2011, 528(1314): 4491-4499.

[25] Gaber A, Ali A M, Matsuda K, et al. Study of the developed precipitates in $\mathrm{Al}-0.63 \mathrm{Mg}-0.37 \mathrm{Si}-0.5 \mathrm{Cu}$ (wt.\%) alloy by using DSC and TEM techniques. J. Alloy. Compd., 2007, 432(1-2): 149-155.

[26] Deschamps A, Militzer M, Poole W J. Precipitation kinetics and strengthening of a Fe-0.8wt.\% Cu alloy. ISIJ Int., 2001, 41(2): 196-205.

[27] Bhagat A N, Pabi S K, Ranganathan S, et al. Aging behaviour in copper bearing high strength low alloy steels. ISIJ Int., 2004, 44(1): 115-122.

[28] Rana R, Bleck W, Singh S B, et al. Development of high strength interstitial free steel by copper precipitation hardening. Mater. Lett., 2007, 61(14-15): 2919-2922.

[29] Jain D, Isheim D, Hunter A H, et al. Multicomponent highstrength low-alloy steel precipitation-strengthened by subnanometric $\mathrm{Cu}$ precipitates and $\mathrm{M}_{2} \mathrm{C}$ carbides. Metall. Mater. Trans. A, 2016, 47(8): 3860-3872.

[30] Dhua S K, Mukerjee D, Sarma D S. Influence of tempering on the microstructure and mechanical properties of HSLA-100 steel plates. Metall. Mater. Trans. A, 2001, 32(9): 2259-2270.

[31] Dhua S K, Mukerjee D, Sarma D S. Influence of thermomechanical treatments on the microstructure and mechanical properties of HSLA-100 steel plates. Metall. Mater. Trans. A, 2003, 34(2): 241-253.

[32] Xi T, Shahzad M B, Xu D, et al. Copper precipitation behavior and mechanical properties of $\mathrm{Cu}$-bearing $316 \mathrm{~L}$ austenitic stainless steel: A comprehensive cross-correlation study. Mater. Sci. Eng. A, 2016, 675: 243-252.

[33] Xi T, Shahzad M B, Xu D, et al. Effect of copper addition on mechanical properties, corrosion resistance and antibacterial property of 316L stainless steel. Mater. Sci. Eng. C-Biomimetic Supramol. Syst., 2017, 71: 1079-1085.

[34] Jiao Z B, Luan J H, Zhang Z W, et al. Synergistic effects of Cu and $\mathrm{Ni}$ on nanoscale precipitation and mechanical properties of high-strength steels. Acta Mater., 2013, 61(16): 5996-6005.

[35] Jiao Z B, Luan J H, Miller M K, et al. Precipitation mechanism and mechanical properties of an ultra-high strength steel hardened by nanoscale $\mathrm{NiAl}$ and $\mathrm{Cu}$ particles. Acta Mater., 2015, 97: 58-67.

[36] Kapoor M, Isheim D, Ghosh G, et al. Aging characteristics and mechanical properties of $1600 \mathrm{MPa}$ body-centered cubic $\mathrm{Cu}$ and B2-NiAl precipitation-strengthened ferritic steel. Acta Mater., 2014, 73: 56-74. 
[37] Li Z H, Chai F, Yang L, et al. Mechanical properties and nanoparticles precipitation behavior of multi-component ultra high strength steel. Mater. Des., 2020, 191: 108637.

[38] Song C J, Xia W B, Zhang J, et al. Microstructure and mechanical properties of Fe-Mn based alloys after sub-rapid solidification. Mater. Des., 2013, 51: 262-267.

[39] Song C J, Lu W, Xie K, et al. Microstructure and mechanical properties of sub-rapidly solidified $\mathrm{Fe}-18 \mathrm{wt} \% \mathrm{Mn}-\mathrm{C}$ alloy strip. Mater. Sci. Eng. A, 2014, 610: 145-153.

[40] Song C J, Yang Y, Guo Y Y, et al. Solidification characteristics of $\mathrm{Fe}-\mathrm{Ni}$ peritectic alloy thin strips under a near-rapid solidification condition. China Foundry, 2015, 12(3): 189-195.

[41] Zhang J L, Hu C H, Zhang $\mathrm{Y} \mathrm{H}$, et al. Microstructures, mechanical properties and deformation of near-rapidly solidified low-density Fe-20Mn-9Al-1.2C- $x$ Cr steels. Mater. Des., 2020, 186: 108307.

[42] Liu L B, Li C M, Yang Y, et al. A simple method to produce austenite-based low-density Fe-20Mn-9Al-0.75C steel by a near-rapid solidification process. Mater. Sci. Eng. A, 2017, 679: 282-291.

[43] Yang Y, Zhang J L, Hu C H, et al. Structures and properties of Fe-(8-16) Mn-9Al-0.8 C low density steel made by a centrifugal casting in near-rapid solidification. Mater. Sci. Eng. A, 2019, 748: 74-84.

[44] Yang R, Xia W B, Song C J, et al. Phase formation of Fe-Mn binary alloy during sub-rapid solidification. Adv. Mater. Res., 2012, 391: 741-744.

[45] Chen S P, Rana R, Haldar A, et al. Current state of Fe-Mn-Al-C low density steels. Prog. Mater. Sci., 2017, 89: 345-391.
[46] Ohkubo N, Miyakusu K, Uematsu Y, et al. Effect of alloying elements on the mechanical properties of the stable austenitic stainless steel. ISIJ Int., 1994, 34(9): 764-772.

[47] Dumay A, Chateau J P, Allain S, et al. Influence of addition elements on the stacking-fault energy and mechanical properties of an austenitic Fe-Mn-C steel. Mater. Sci. Eng. A, 2008, 483-484: 184-187.

[48] Mulholland M D, Seidman D N. Nanoscale co-precipitation and mechanical properties of a high-strength low-carbon steel. Acta Mater., 2011, 59(5): 1881-1897.

[49] Jiao Z B, Luan J H, Miller M K, et al. Co-precipitation of nanoscale particles in steels with ultra-high strength for a new era. Mater. Today, 2017, 20(3): 142-154.

[50] Heinze M H. The effect of aging treatment on the microstructure and properties of copper-precipitation strengthened HSLA steel. Master. Thesis, California: Naval Postgraduate School, 1988: 7-8.

[51] Wang X L, Zhang W N, Liu Z Y, et al. Improvement on roomtemperature ductility of $6.5 \mathrm{wt} . \% \mathrm{Si}$ steel by stress-relief annealing treatments after warm rolling. Mater. Charact., 2016, 122: 206-214.

[52] Sohn S S, Lee B J, Lee S, et al. Effects of aluminum content on cracking phenomenon occurring during cold rolling of three ferrite-based lightweight steel. Acta Mater., 2013, 61(15): 5626-5635.

[53] Sohn S S, Lee B J, Lee S, et al. Microstructural analysis of cracking phenomenon occurring during cold rolling of (0.1-0.7) C-3Mn-5Al lightweight steels. Met. Mater. Int., 2015, 21(1): 4353. 